\title{
Some Observations on
}

\section{Competency Based Instruction}

\author{
REUBEN ALTMAN \\ EDWARD L. MEYEN
}

\begin{abstract}
This article summarizes the authors' observations derived over the course of 3 years of research and experimentation with competency based instruction. While the intent of this project has been the development of a prototype graduate level training model to prepare curriculum consultants for exceptional children, the model, processes, and experiences are generalizable to the range of training needs in special education. The primary goals of the project involve (a) the establishment of an empirical basis for the identification of competencies and (b) the design of instructional modules as the principal mode of training. The observations reported here are categorized into four areas of concern: developmental processes, module features, student response, and program concerns.
\end{abstract}

Since Fall 1970 the Department of Special Education at the University of MissouriColumbia has been engaged in developing a competency based training program to prepare curriculum consultants for the education of exceptional children. In contrast to those situations where the transition to competency based teacher education (CBTE) is done with existing faculty and financial resources, this project was funded in part through the Division of Training Programs, Bureau of Education for the Handicapped, US Office of Education. Consequently, it became feasible to commit resources to tasks related to researching competencies, transformation of competencies into program specifications, and the develop- ment of modules. The training program is now operational with students enrolled in modules.

Published reports detailing procedures and data on the research phase (Altman, Chandler, Connolly, \& Meyen, 1971) and the module specifications phase (Meyen, Altman, Chandler, \& Howard, 1973) are available. A descriptive summary of the project has also recently been reported by Meyen and Altman (1973). This article presents staff observations based on the experience in researching competencies, developing modules, and initiating and conducting a competency based training program. We feel that these observations warrant being shared with other persons engaged in planning or implementing competency based training programs. While this program is specific to graduate level training and geared to the preparation of support personnel, the procedures employed are highly generalizable to teacher training programs.

\section{Project Goals}

The following brief description of the project goals is presented as a frame of reference. The curriculum consultant being trained has been defined as an individual capable of representing the interests of exceptional children at the decision making level in curriculum development activities. In contrast to providing direct services to children,

Reuben Altman is Assistant Professor and Director, Special Education Curriculum Training Center, Department of Special Education, University of Missouri-Columbia; and Edward L. Meyen is Professor and Chairman, Department of Special Education, University of Kansas, Lawrence. Preparation of this article was supported by Grant No. OEG-0-70-4808 (603) from the Division of Training, Bureau of Education for the Handicapped, US Office of Education. 
these consultants will function in the role of support personnel for teachers and administrators in general and special education who are responsible for decisions affecting the education of exceptional children.

The intent is not to provide additional training in special education techniques. Instead, the goal is to select individuals with demonstrated instructional skills and to provide them training experiences in such generic areas as evaluation, development, materials and media, and support systems. In essence, the goal is to develop a competency based training program in module format which integrates the teaching of curriculum development skills and knowledge with an orientation toward instruction for exceptional children.

Specifically, the project is committed to the following:

1. The systematic identification of competencies through empirical research.

2. The design of instructional modules based on identified competencies.

3. The packaging of modules in a form which facilitates their use by other training institutions and agencies providing both preservice and inservice education.

4. Training in the processes of curriculum development with generic application to educational programs for exceptional children.

The observations which follow have been grouped according to four functional areas: development, module features, student response, and program concerns. This categorization is merely for clarification and in no way implies a ranking of importance. It should also be noted that the emphasis is on those observations which might be helpful to others engaged in similar activities rather than on documentation of the success of the project.

\section{Developmental Processes}

Historically, curriculum development in higher education has occurred as a result of professors organizing individual courses, with the cumulative effort being the structuring of training programs. Until recently there has been little evidence of systematic curriculum development in higher education. The advent of CBTE has stimulated considerable activity in this area. At least four development related observations have surfaced which merit discussion.

\section{Procedures for Competency Identification}

There has been a tendency to rely on intuitive processes in the determination of competencies relative to various competency based programs. In contrast, it is possible to design systematic procedures for identifying competencies, which, while not infallible, do provide more confidence and direction than the mere delineation of competencies based on intuition. Our approach was to go beyond searching the literature in education for competency identification and explore relevant literature in sociology, psychology, and business. We also conducted a series of structured interviews with consumers of services provided by curriculum consultants. Both of these tasks were guided by the competency generation and organization model presented in Figure 1.

The intent of this model was to bring order to the competencies which were being identified and to direct our attention to functions and contexts considered relevant to the role of a curriculum consultant. This model enhanced identification of a representative pool of relevant competencies, enabled the elimination of redundancies, and facilitated the rendering of competency statements to a reasonable level of uniformity and specificity.

\section{Gathering of Field Information}

The eliciting of information from the field adds significantly to the competency identification process. Of equal importance is the relationship it helps develop with consumers of the training product. In this project 100 representative competencies from the item pool were examined by 587 public school personnel in nine different educational roles (see Table 1). School districts were randomly selected from 11 Midwestern states.

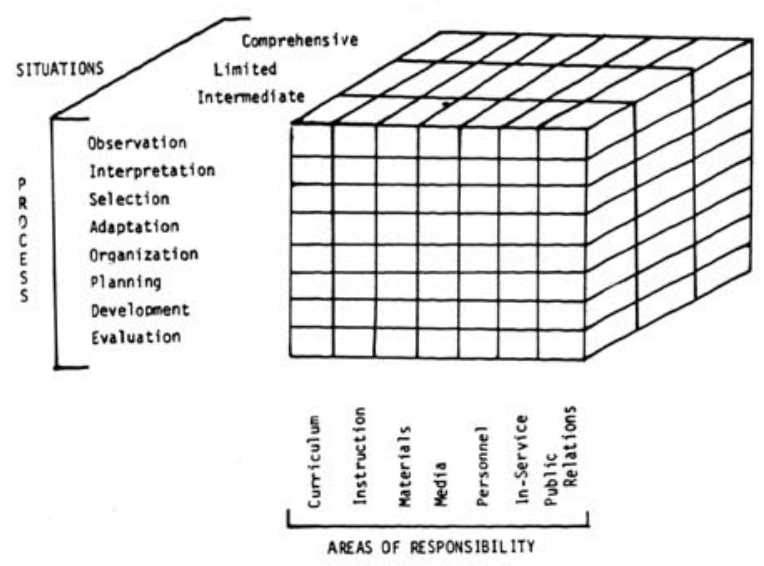

FIGURE 1. Competency organization and generation model. 


\begin{tabular}{lccccc}
\hline \hline & \multicolumn{5}{c}{ Size of District } \\
& $\begin{array}{c}\text { Inter- } \\
\text { mediate }\end{array}$ & $25,000+$ & $\begin{array}{c}10,000- \\
24,999\end{array}$ & $\begin{array}{c}5,000- \\
9,999\end{array}$ & $\begin{array}{c}\text { Row } \\
\text { total }\end{array}$ \\
Position & 0 & 1 & 3 & 13 & 17 \\
\hline Superintendent & 5 & 2 & 3 & 9 & 19 \\
Psychologist & 0 & 3 & 10 & 33 & 46 \\
Principal & 0 & 2 & 2 & 8 & 12 \\
Curriculum consultant & 8 & 5 & 11 & 23 & 47 \\
Speech and/or hearing clinician & 8 & 2 & 3 & 3 & 16 \\
Special education consultant & 4 & 2 & 5 & 8 & 19 \\
Director of special education & 61 & 29 & 76 & 106 & 272 \\
Special education teacher & 0 & 9 & 24 & 106 & 139 \\
Regular elementary teacher & 86 & 55 & 137 & 309 & 587 \\
Column total & & & & & \\
\end{tabular}

The questionnaire used sought two kinds of responses: (a) an importance ranking and (b) a trainability index. Respondents ranked the importance dimensions on a scale from 0 to 4 and indicated trainability as follows: $O C$ for best developed through on-campus curriculum; $J T$ for best developed through on-the-job training and experience; and $S G$ for not amenable to training (a matter of self growth and personal maturity).

The analyses of these importance and trainability data from the perspective of respondent position and size of school district yielded meaningful guidelines for both module development and student counseling relative to their training objectives. The results of this phase of the project are detailed and available elsewhere (Altman et al., 1971). In addition to the data derived from this process, we gained access to field settings and potential practicum sites which otherwise would have been gained only after considerably greater effort.

\section{Curriculum Development}

Curriculum development is an activity which may be inordinately time consuming for faculty members. In spite of the emphasis on systematic instruction and curriculum development provided preservice students in their courses, teacher educators have little experience in applying task analysis procedures to the development of their own instructional program.

We found the initiation of this activity to be extremely difficult. While having previously identified and organized the competencies facilitated the process, we experienced a number of false starts. It was not until we adopted a systematic specification process and collectively began to reduce competencies to a series of interrelated behavioral objectives that we began to make real progress. The specification process, graphically presented in Figure 2, resulted in specific guidelines for module development.

As helpful as the specification process was in delineating the curriculum and structuring requirements for the respective modules, the activities inherent in module development still proved to be substantial. It soon became clear that there was little in our past experiences which could be drawn upon in the actual writing of modules. The "nitty-gritty" task of module development was a new dimension of our professional roles.

This opens the door to the question of whether a professor can effectively teach a module developed by another professor. It may be that either the ego involvement or knowledge which goes with creating a module is 
essential to teaching that module. There is considerable risk of influencing negative attitudes toward module development and instruction if the task is carried out under less than desirable circumstances.

\section{Inspection by Others}

Once the training program is in module format or at least specified in behavioral objectives, it is open for inspection by students, colleagues, consumers, and pedestrian critics. This appears to be one of the biggest hurdles to overcome. While modules are always open to revision, the mere fact that they require the majority of the instruction to be imbedded in a written context raises anxieties. The labeling of modules as "rough draft," "not for distribution," etc., is no deterrent to theft, scrutiny by others, and at times premature judgment on the quality or significance of the activity being described. We finally agreed that in the long run it was better to swallow our pride and begin field testing module activities, suspecting that many were inappropriate and below our capabilities, rather than resist release until they satisfied our personal requirements for scholarly work. While this procedure occasionally results in embarrassment, it facilitates production and encourages generation of a wider range of activities. The professor's concern for his own scholarly stature may at times stifle his creativity.

\section{Module Features}

An early problem encountered in the process of module development was the selection of a format and the determination of what should constitute a module of instruction. If one examines the range of modules being produced, it becomes apparent that considerable variance exists in terms of the structure and comprehensiveness of modules. They range from units of instruction in the form of behavioral objectives with accompanying criterion measures to self contained independent study packages.

For our purposes it seemed important to develop a format which allowed a number of interrelated skills to be developed as a unit and which allowed the acquisition of rather substantive skills as opposed to highly specific discrete tasks. Thus, while our modules include the delineation of activities for individual behaviorally stated objectives, they are subsumed under larger units of instruction.

In effect, our modules are instructional

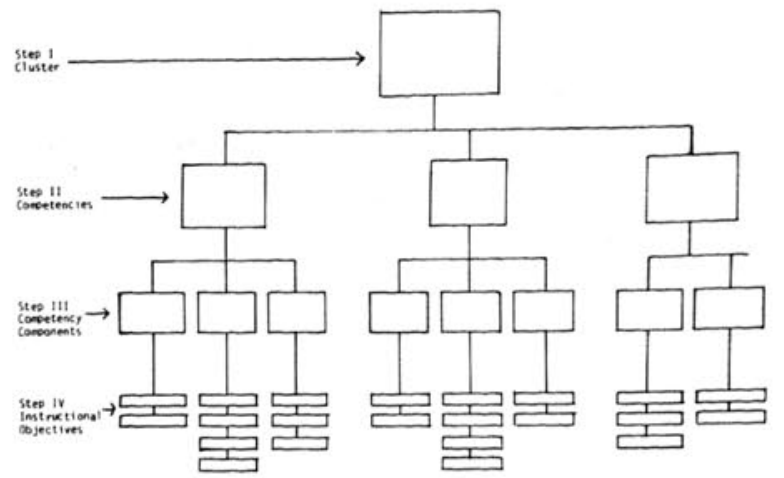

FIGURE 2. Competency specification process.

packages. A module topic might be as global as "Evaluating Materials and Media" or "Developing Curriculum." Within this context we have structured module elements, with each module element being equivalent to a single competency. Module elements are broken down into competency components, which are in turn comprised of behavioral objectives. It is at this behavioral objective level that instructional activities are designed.

The problems encountered in the actual development of modules have been alluded to previously. It would be presumptuous to suggest that the task is easy or that it does not require a major investment of resources. Beyond these concerns at least four additional observations relative to design features deserve attention.

First, when designing a module which requires students to progress independently, there is a tendency to inadvertently become a little "cookbookish." In writing a module, particularly where the student is given considerable information input through the enabling activity, a developer can fall into the trap of assuming the student knows nothing about the skills or the context in which those skills will be applied. The result is a gross oversimplification of instruction with unnecessary information conveyed. It requires some experience at module development to restrict enabling activities to a single meaningful objective.

Second, in examining our early attempts at module development, we found much redundancy in the use of particular activities. This may have occurred because of bias for a particular kind of experience, lack of creativity, or merely failure to monitor the kinds of activities built into the module. Feedback from students suggests that variability as well as relevance is essential to their maintaining a high interest in module performance. 
Third, with limited access to local school settings it is difficult to control the amount of trainee traffic into the schools for module activities. Although one can restrict the number or extensiveness of student visits to schools when designing a module, once the module is offered to students, the control is lost. This occurs because students progress at varying rates through the same module and there may be several students in the same module needing to go into the schools for different reasons. This problem is compounded where several modules are being offered at the same time. Informal ground rules become essential; ideally, students monitor their own traffic by maintaining awareness of who else is working in the schools and pairing up where feasible. Whenever possible, it may be preferable to use simulation techniques to circumvent inundation of local schools.

Fourth, the most troublesome feature of module instruction for the professor, in our experience, has been keeping up with the evaluation of student performance. Student performance is evaluated on an individual basis, and even with as few as 10 students in a module this becomes a major task.

In this project students have not been encouraged to evaluate their own work because we feel the student-instructor interaction is crucial. As a partial compromise weekly seminar sessions which serve as group interaction sessions have been set up. Individual sessions continue to be held at a student's request. Usually this occurs when he has completed a group of related activities or when successful performance on an activity is prerequisite to entering a subsequent activity.

\section{Student Response}

Usually module instruction is a new experience for students. They may have previously encountered some independent study but nothing comparable to the nature of modules. For the most part it appears difficult for them to become acclimated to this form of instruction. This is not to imply that it has been a negative experience, although that may be true in individual cases.

Module instruction does place the student in an unaccustomed role. Modules place the responsibility for learning on the student; he has to initiate the activity and carry through. If he fails to produce, he does not progress. No longer does he complete requirements on a temporal basis by class attendance. It takes a certain amount of aggressiveness and a great deal of self initiative to function effectively in this type of instructional situation.

Interestingly enough, student behavior does change and most students do adapt as they receive reinforcement from their production. Some of the difficulties involved in this adaptation follow.

First, in spite of the explicit directions built into module activities, many students still feel that the expected performance is not clear. Their response under these circumstances is to overproduce. This is disturbing to them when they realize that less effort on their part would have been sufficient for meeting performance criteria.

Second, when several students are working simultaneously on the same module, there is a tendency for them to pace themselves. At times one suspects a conspiracy. However, once some self confidence is achieved, this breaks down and greater variability in rate of progress is evidenced.

Third, the requirements for study conditions change in module instruction. No longer does the classroom serve as the primary setting in which instruction takes place. It has been our experience that space needs to be made available to students which is sufficiently flexible to accommodate their instructional needs. We have designated one study facility exclusively for student use, and it is under their control. Media equipped carrels and necessary resources are stored in this room. Students are provided keys to the facility so that they have access to resources and the study area at times convenient to their personal schedules. This degree of independence must be provided if we are to convince them of our sincerity in fostering self initiated learning.

Fourth, although students represent the primary source of feedback for the revision of modules, we have observed that this becomes a difficult procedure to formalize. Therefore, we have implemented several specific procedures to encourage student input. For example, a log is kept on the time required to complete each activity; evaluation sheets are completed on selected activities; and students are asked to develop alternative activities for those they judge to be inappropriate or ineffective.

\section{Program Concerns}

Most of our energies to this point have been devoted to the processes of competency identification, module development, and the 
field testing of modules. While we have established certain procedures, we have resisted the temptation to routinize patterns for the flow of students through the program. For example, we decided it was best not to negotiate for module course numbers or establish credit values and catalog listings until we had substantial support for the kinds of changes necessary to accommodate a module system.

\section{Prediction of Time Needed}

The most obvious error we have made thus far has been in predicting the time and energy required to complete a module. Our estimates were grossly under what students have reported. At this point we are still in the process of determining to what extent our estimates are off compared to student perceptions regarding what constitutes reasonable output.

The long established pattern of a student earning 3 hours of credit by attending class 3 hours per week with outside study when necessary appears to be working against us. Instead of giving grades at the end of the semester, in most cases we provide for delayed grades without penalty so that time can remain a variable rather than a constraint. This year's experience will allow us to make better estimates on credit values. Once such information is available, we will be in a better position to establish formal procedures for programing.

\section{Student Record Keeping}

We have attempted to integrate provisions for record keeping on student performance into the design of the modules. Since our modules represent clusters of behavioral objectives and related activities, when a student satisfies a competency, he is in effect satisfying a series of objectives. Our concern is to monitor the student's progress through units larger than objectives without losing sight of performance relative to individual objectives. Thus, in satisfying the requirements of the larger units, performance on objectives is also assessed. Our goal in this area has been to keep the record system simple and within the control of the student.

\section{Faculty Role}

The final observations pertain to faculty role. This topic merits an entire article, but for purposes of this discussion our experience suggests that:
1. The faculty time required to develop modules is extreme, and the time demands for teaching modules is not substantially less than that for traditional instructional methods.

2. The faculty has more information available on what is included in other modules and thus avoids redundant instruction.

3. The nature of faculty-student interaction changes. In the more traditional approach, the interaction is often restricted to group encounters and only the more aggressive students are assured of individual attention. A module approach provides more personal interaction on a one to one basis for all trainees. It has been our observation that the student becomes more aware of the professional interests and activities of the instructor under these circumstances.

\section{Concluding Comments}

The observations reported here are representative of our experience in establishing a competency based program to prepare curriculum consultants for the education of exceptional children. In some cases, the implications are obvious; in others, they suggest cues for further study. There has been insufficient time to assess the effectiveness of the program on students. However, our appraisal of the processes inherent in developing a competency based program has made us exceedingly conscious of the need for systematic curriculum development in higher education. Certainly, the procedures we have employed have facilitated our delineation of a curriculum, and they have also forced us into reality checks as we assess competencies against consumer expectancies. It is our hope that this summary of observations and experiences will help others currently pursuing the development of competency based training programs.

\section{References}

Altman, R., Chandler, M. R., Connolly, A. J., \& Meyen, E. L. Interim report: Competency research phase. Columbia: University of Missouri Special Education Curriculum Training Center, 1971.

Meyen, E. L., \& Altman, R. Individualizing instruction for preservice teachers: An applicable competency based training model. Focus on Exceptional Children, 1973, 5, 1-11.

Meyen, E. L., Altman, R., Chandler, M. R., \& Howard, C. L. Interim report: Module specification phase. Columbia: University of Missouri Special Education Curriculum Training Center, 1973. 